\title{
CONSTRUÇÃO DE UM CALORÍMETRO PARA MEDIÇÃO DE EFICIÊNCIA TÉRMICA NA SOLDAGEM
}

\author{
C. Ziegler, T. Sinigaglia* e A. J. Patias
Universidade Federal de Santa Maria (UFSM) / Programa de Pós-Graduação em Engenharia de Produção
Ts001117@fahor.com.br ${ }^{*}$ \\ Submetido 04/04/2016 - Aceito 28/09/2017 \\ DOI: $10.15628 /$ holos.2017.4368
}

\section{RESUMO}

Calorímetro é um sistema utilizado para a medição de transferência de calor. O objetivo do presente trabalho consiste na construção de um calorímetro para medir a eficiência térmica na soldagem que foi desenvolvido nos laboratórios da Faculdade Horizontina-FAHOR. O calorímetro consiste em duas caixas isoladas termicamente sendo que em uma delas está acondicionada uma tubulação aletada, que tem a função de coletar o calor do experimento. Após a construção do calorímetro foram realizados testes experimentais para validação dos mesmos. Dois testes foram realizados primeiramente com peças aquecidas para verificação da eficiência térmica do calorímetro. Posteriormente, foi realizado um teste com soldagem MAG para definição do rendimento térmico do calorímetro. No primeiro experimento com peças aquecidas foi determinada que a eficiência térmica do calorímetro foi de $92,8 \%$, no segundo teste, a eficiência térmica do calorímetro foi de $91,72 \%$. No experimento de soldagem foi encontrado um rendimento térmico de $88,73 \%$. Por este motivo, pode-se afirmar que o objetivo ao qual o trabalho se propôs foi atingido, pois o calorímetro mostrou-se capaz, inclusive, de medir a eficiência térmica de soldagem.

PALAVRAS-CHAVE: Calorimetria, Eficiência térmica, Soldagem MAG.

\section{CONSTRUCTION OF A CALORIMETER FOR MEASURING THERMAL EFFICIENCY WELDING}

\begin{abstract}
Calorimeter is a system used for measurement of heat transfer. The objective this study is to construct a calorimeter to measure the thermal efficiency in welding which was developed at the Faculty HorizontiaFAHOR laboratories. The calorimeter consists of two thermally isolated cases and in one of them is wrapped finned pipe, which has the function of collecting the heat of the experiment. After construction of the calorimeter experimental tests for validation thereof were performed. Two tests were performed first with heated pieces to verifying the thermal efficiency of the
\end{abstract}

calorimeter. Subsequently, a test of MAG welding for defining the thermal efficiency of the calorimeter was performed. In the first experiment was heated pieces was determined that the thermal efficiency of the calorimeter was $92.8 \%$ in the second test, the thermal efficiency of the calorimeter was $91.72 \%$. In the experiment we found a welding thermal efficiency of $88.73 \%$. For this reason, it can be stated that the goal to which the work proposed was reached because the calorimeter was capable even of measuring the thermal efficiency of welding.

KEYWORDS: Calorimetry, Thermal efficiency, MAG welding. 


\section{INTRODUÇÃO}

Nos processos de fabricação, a soldagem, a partir do momento em que foi desenvolvida, ocupou importante papel no setor metal mecânico. As indústrias são os responsáveis pelo crescimento e utilização deste processo.

Um fenômeno de grande importância que ocorre no decorrer dos processos de soldagem é o aporte térmico, pelo fato da imposição de calor para a peça estar ligado de forma direta às propriedades mecânicas obtidas na junta soldada, e com as mudanças metalúrgicas ocorridas durante o processo. A transferência de calor também está associada ao ciclo térmico da soldagem.

A eficiência térmica nos processos de soldagem tem importante papel no que se refere a características da solda, pois com a medição da eficiência térmica, pode-se obter um maior controle sobre a geometria, a profundidade e a penetração do cordão de solda.

Para o estudo e quantificação do calor aportado na peça de trabalho, tem-se utilizado tanto métodos teóricos (analíticos e numéricos), quanto experimentais (calorimetria).

O aparelho específico para determinação da eficiência térmica na soldagem é conhecido como calorímetro, o qual consiste em um sistema utilizado na medição de transferência de calor. Para fins de avaliação da eficiência térmica no processo de soldagem foram desenvolvidos métodos experimentais, utilizando-se processos calorimétricos. Os resultados que são obtidos empregando os métodos calorimétricos experimentais mostram grande nível de satisfação, pelo fato de nelas estarem contidas as principais variáveis do processo de soldagem e os métodos numéricos e analíticos são muito limitados ao modelo utilizado e às aproximações realizadas.

O presente trabalho tem por objetivo geral a construção de um calorímetro para medir a eficiência térmica do processo de soldagem, especificamente pretende-se construir o calorímetro. $\mathrm{O}$ passo seguinte é medir a capacidade térmica do calorímetro e também testar o calorímetro para medir a eficiência térmica do processo de soldagem MAG.

Justifica-se pela importância da medição da eficiência térmica da soldagem, pois com a obtenção do valor da eficiência térmica da soldagem é possível realizar a verificação em características da soldagem, como a variação da geometria do cordão de solda, variação nas propriedades mecânica da solda e um controle das distorções que ocorrem no material durante o processo de soldagem.

\section{REVISÃO DE LITERATURA}

\subsection{Principais tipos de calorímetros}

Os calorímetros utilizados para estudar o aporte térmico nos processos de soldagem são de vários tipos diferentes, dentre eles o de resfriamento contínuo da água, de escoamento contínuo da água, recipiente com isolamento (sem contato ou interferência do ambiente externo) preenchido com água e termopares que monitoram a temperatura interna, desenvolvidos seguindo os avanços da tecnologia e do material disponível para sua construção e empregabilidade (AREVALO \& VILARINHO, 2012). 
Um dos calorímetros mais conhecidos e utilizados para fins de avaliação de rendimento no processo de soldagem tem como base o princípio do resfriamento contínuo da peça com água. Os pioneiros neste tipo de experimento foram Essers e Walter (1981), que mantiveram uma chapa de aço imersa, de forma parcial, na água, ficando exposta apenas a superfície na qual seria efetivada a soldagem. Durante a experimentação, no interior do equipamento, água era constantemente agitada e misturada por um agitador com a finalidade de garantir que a temperatura da água no interior do calorímetro permanecesse homogênea. A água monitorada durante todo o processo atingiu um valor máximo de $35^{\circ} \mathrm{C}$. Um esquema possível de representar o calorímetro em questão pode ser observado na Figura 1.

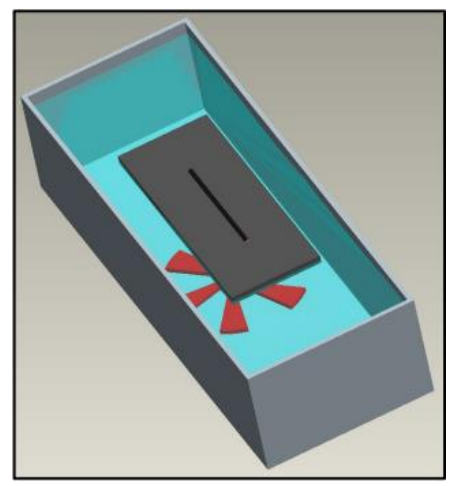

Figura 1: Calorímetro de resfriamento contínuo. Fonte: Esser e Walter, 1981.

Um calorímetro de escoamento contínuo de água foi construído em 1989 por Lu e Kou, sendo que neste, a temperatura da água era medida na entrada e na saída do equipamento, empregando para isso termopares. Neste experimento o fluxo de água fica em contato com a face oposta do corpo onde é efetuada a solda, montada no topo de uma caixa de aço inoxidável.

Neste experimento (de escoamento de água contínuo), a eficiência térmica obtida foi maior que no experimento realizado por Esses e Walter em 1981. A diferença na eficiência térmica obtida foi atribuída às propriedades do alumínio - material base - utilizado na realização do experimento.

Para fins de determinação do rendimento térmico da solda $(\eta T)$, foi usada a técnica da calorimetria, onde as quantidades de calor transferidas a peça podem ser avaliadas, utilizando-a se a metodologia conhecida como calorímetro "molhado", no caso o calorímetro cuja construção propõem-se o presente trabalho. Segundo Kou (2002), a eficiência térmica está entre 30 a 90\%.

$\mathrm{Na}$ técnica proposta anteriormente, a fonte de calor move-se a velocidade (Vs), pela tubulação aletada por onde passa a água com uma vazão conhecida (W). A temperatura é monitorada por termopares na entrada (To) e na saída da mangueira condutora de água (Tf). 0 rendimento térmico do processo de soldagem MIG/MAG (GMAW) deve estar entre 75\% e 95\% (MODENESI et al., 2012). Assim sendo será utilizada a Equação 1 para determinar o rendimento térmico:

$\eta t \times P \times t s=\int_{0}^{b} w \times c \times \Delta t \times d t$

Onde:

$\mathrm{P}=$ potência de solda $(\mathrm{W})$; 
ts= tempo (s);

$w=\operatorname{vazão}\left(\mathrm{m}^{3} / \mathrm{s}\right)$

$\Delta \mathrm{t}=$ variação de temperatura $\left({ }^{\circ} \mathrm{C}\right)$;

$\mathrm{C}=$ calor específico da água $\left(\mathrm{J} / \mathrm{Kg} .{ }^{\circ} \mathrm{C}\right)$.

A área do gráfico da Figura 2 corresponde à variação esquemática entre a temperatura de entrada e saída em cada intervalo de tempo, sendo que foram realizadas várias medições de tempo e temperatura até conclusão da medição.

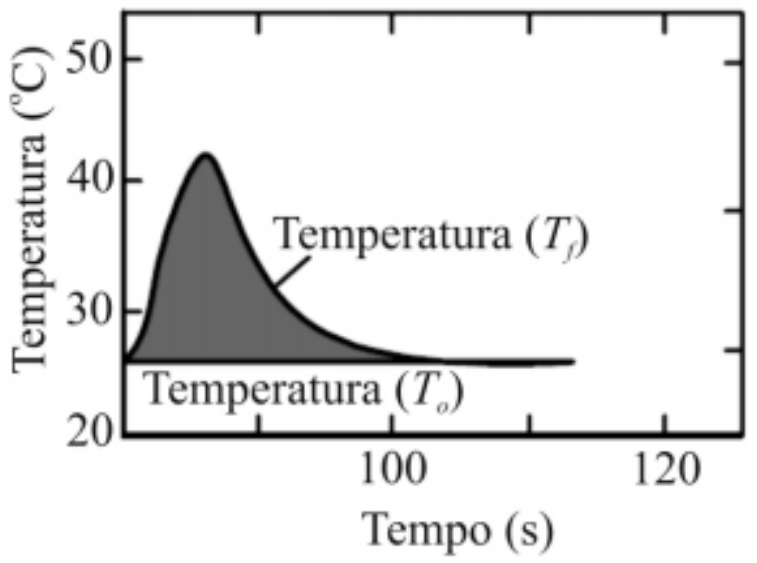

Figura 2: Variação da temperatura de entrada e saída de água do calorímetro em função do tempo Fonte: Kou, 2002.

A eficiência térmica $(\eta)$ de um calorímetro consiste na divisão do calor cedido pelo calorímetro (Qcedido) pelo calor recebido pelo calorímetro (Qrecebido) multiplicado por 100 (para obtenção da porcentagem), conforme Halliday, Resnick eWalker (1999), na Equação 2.

$\eta=\frac{\text { Qcedido }}{\text { Qrecebido }} \times 100$

Bosworth (1991) propôs a construção de um calorímetro que consiste num recipiente com isolamento, sem contato ou interferência do ambiente externo, cujo interior é preenchido por água, e contém termopares que monitoram a temperatura interna. Foram padronizados os tempos de soldagem e de intervalo entre o término da solda e a submersão do corpo onde foi efetivado o processo de solda na água, com a finalidade de verificar o aporte de calor no corpo durante a soldagem.

Haelsig, Kusch e Mayer (2012) desenvolveram um calorímetro que também usa água, porém diferente dos anteriores. Era uma placa metálica disposta de forma que uma das extremidades da chapa metálica estivesse a poucos milímetros da lâmina de água e a outra estivesse um pouco mais distante, como pode ser observado na Figura 3. Uma tocha que efetua a soldagem desloca-se paralelamente, começando na parte inclinada que está mais próxima ao nível da água. Conforme a tocha vai se deslocando, eleva-se o nível de água, submergindo a placa metálica. Neste processo, a imersão do cordão produzido é quase instantânea a consolidação da solda. Termopares monitoram a temperatura da água que sai e retorna para o reservatório com o auxílio de uma bomba. 


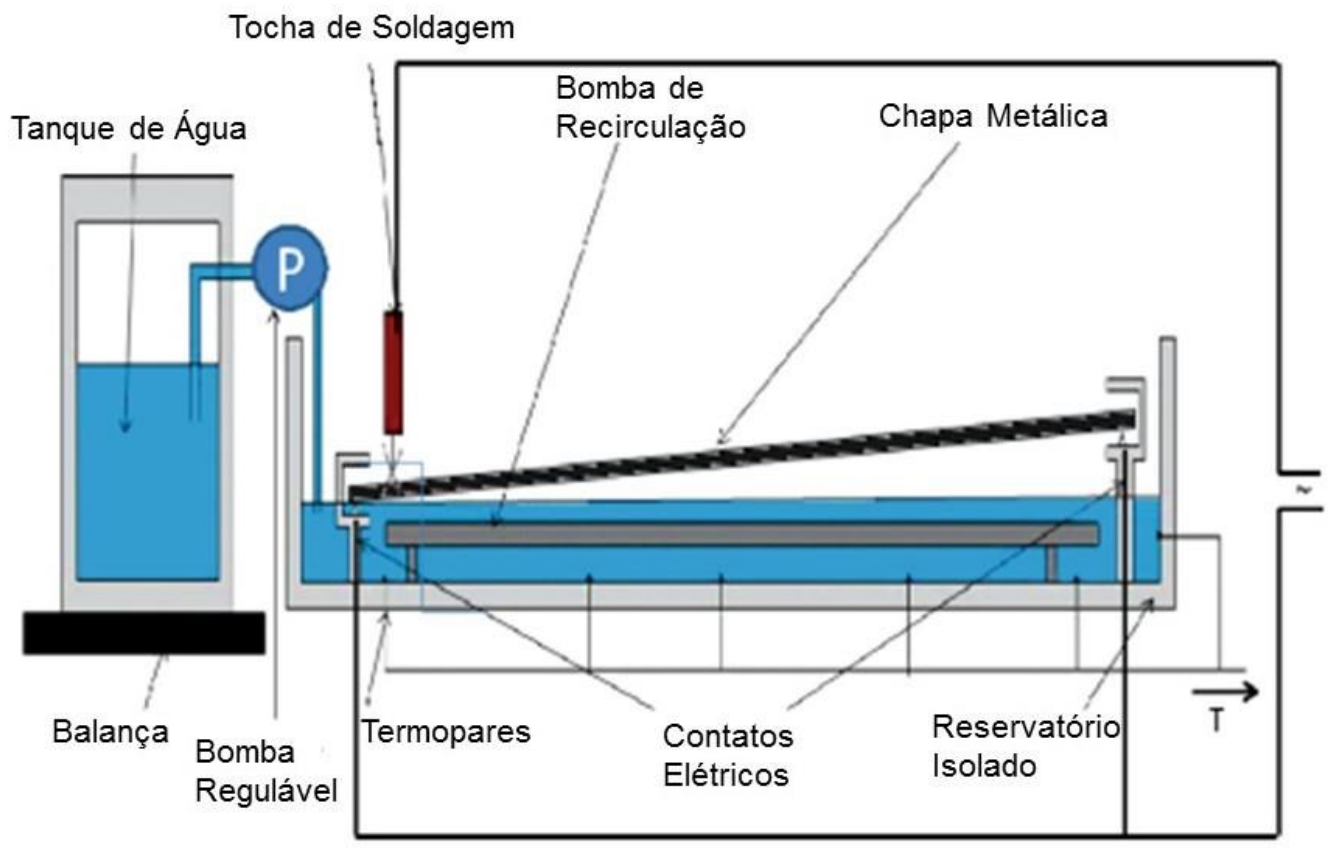

Figura 3: Dispositivo para avaliação do rendimento térmico. Fonte: Haelsig, 2011.

Seguindo princípios e fundamentos termoelétricos de Seebeck e segundos parâmetros de Giedt, DuPont e Marder (1995), construíram um aparelho que continha uma junção termo condutora integrada e influenciada por uma medida de variação de temperatura. Em um dos lados a junção é continuamente resfriada com água, e o outro lado fica diretamente em contato com a peça a ser soldada. A medida de variação de temperatura é obtida através de um par de termopares que estão dispostos cada qual num dos lados da junção.

Deste processo resulta um sinal de tensão. Este é multiplicado por uma medida fixa de calibração, que depende da função da condutividade térmica específica, da espessura e do tipo de termopares que é utilizado no experimento. Todos esses aspectos são responsáveis por determinar o valor da energia que é transferida à peça durante o processo de soldagem. 0 princípio de funcionamento do experimento acima descrito pode ser observado na Figura 4. 


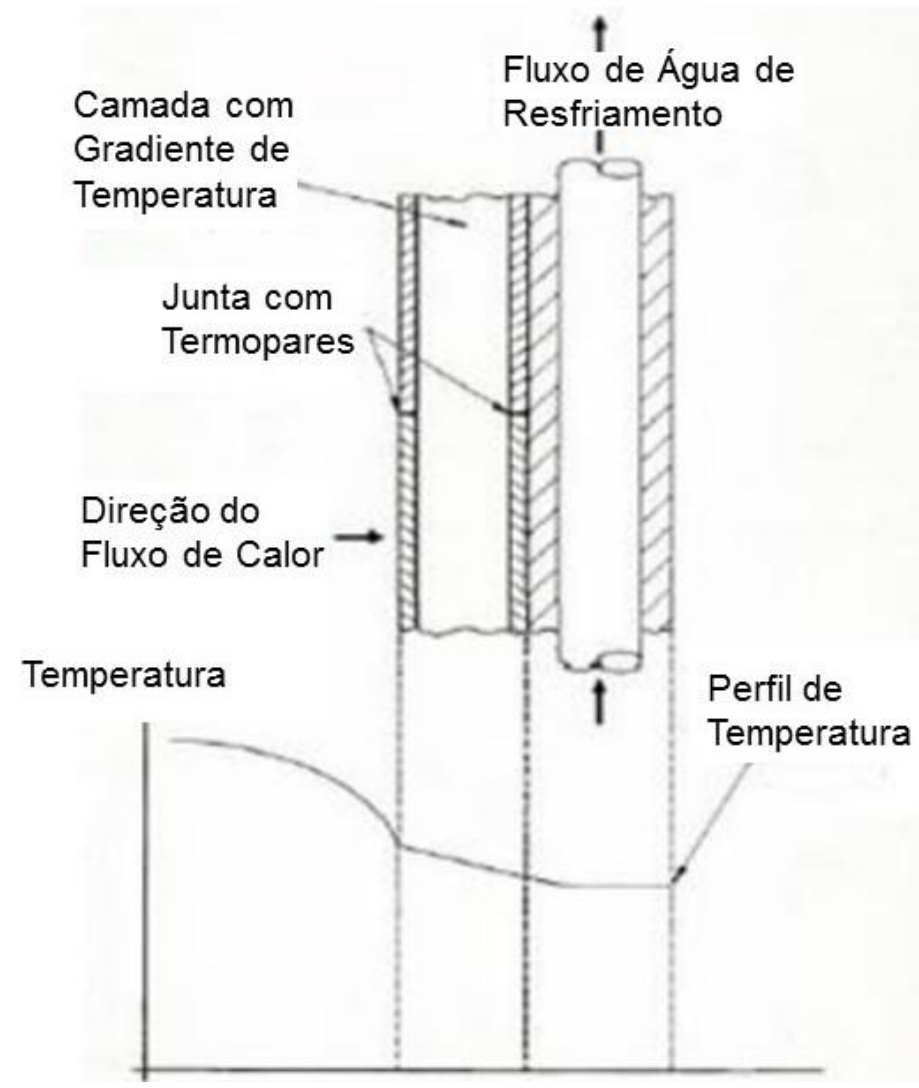

Figura 4: Calorímetro utilizado por DuPont e Marder. Fonte: DuPont e Marder (1995).

Em 1991, seguindo as mesmas características acima descritas, Fuerschbach e Knorovski construíram um calorímetro, onde foi possível observar um rendimento médio de arco de $80 \%$ para o processo MIG/MAG pulsado e convencional.

Cantin e Francis (2005) realizaram experiências usando um calorímetro de caixa fechada, determinando a eficiência térmica na soldagem MIG em alumínio. A caixa tinha uma base de cerâmica, em cima da mesma foi apoiado um bloco de alumínio, onde seria aplicada a solda. 0 espaço que restava sem preenchimento, na caixa, foi preenchido com vermiculita, com fins de isolamento. No alumínio foram colocados outros termopares para monitorar os parâmetros de temperatura que ocorreriam durante o processo de soldagem. $O$ equipamento e sua respectiva montagem podem ser verificados na Figura 5 (os pontos " $x$ " correspondem a posição dos termopares).

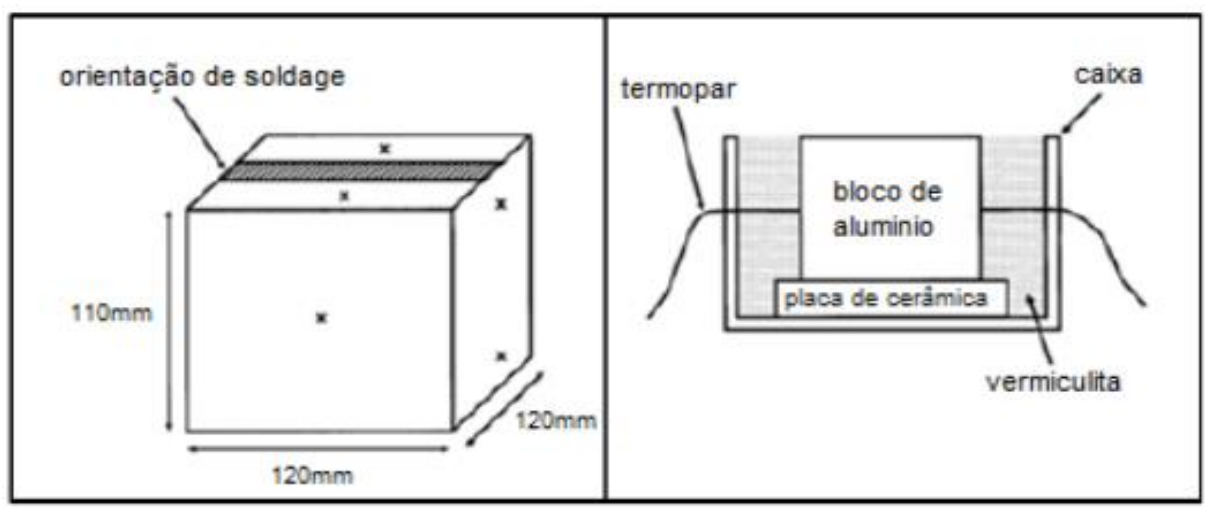

Figura 5: Calorímetro de caixa fechada e seus componentes. Fonte: Cantin e Francis (2005). 
O calorímetro de nitrogênio líquido é a pesquisa mais recente no que se refere ao aporte térmico em processos de soldagem, realizada por Pépe, Lovis e Ségransan (2011).

\section{METODOLOGIA}

A metodologia do presente trabalho compreende as seguintes etapas: primeiramente é descrito como foi construído o calorímetro, em seguida está explicitada a descrição das partes que o compõem o mesmo. Sequencialmente, a descrição de como foram realizados os testes de validação do calorímetro.

\subsection{Construção Do Calorímetro}

O calorímetro foi construído nos laboratórios da Faculdade Horizontina-FAHOR, onde se iniciou com a construção da estrutura do calorímetro que é composta de duas caixas, que são construídas de chapas de aço SAE 1020 com espessura de $2 \mathrm{~mm}$, e unidas por solda MAG. Cada caixa possui as dimensões de 400x400x120 mm expressa na Figura 6 (a).

Sequencialmente, foi montado na caixa inferior do calorímetro, o isolamento térmico, esse é constituído por três camadas, a primeira camada é de isopor de $10 \mathrm{~mm}$ de espessura, a segunda de lã de vidro com $15 \mathrm{~mm}$ de espessura, e a terceira de tijolos refratários de $18 \mathrm{~mm}$ de espessura. Os tijolos foram fixados por parafusos M6 e com argamassa, como pode ser observado na Figura 6 (b).

(a)

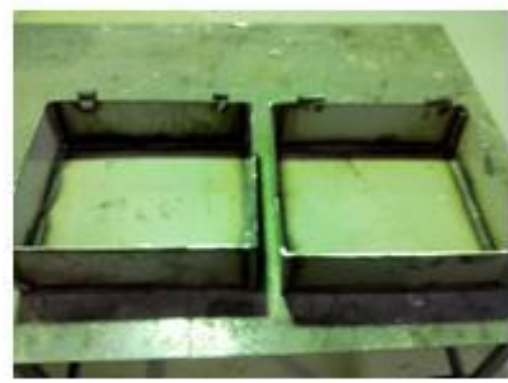

(b)

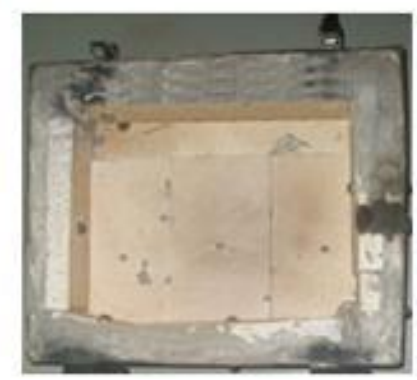

(C)

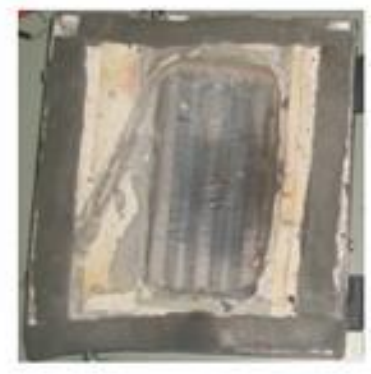

Figura 6: Partes do Calorímetro: (a) tubulação com aletas, (b) caixas de chapa de aço SAE 1020, (c) revestimento térmico.

Após, na caixa superior do calorímetro, foi montado o isolamento térmico, que é composto por três camadas de isolantes: uma de isopor de $10 \mathrm{~mm}$, uma camada de lã de vidro que contorna toda a tubulação aletada (Figura 6 (c)), fixos com parafusos M8. Os tijolos refratários de $18 \mathrm{~mm}$ de espessura foram fixos com parafusos M6 e argamassa.

Posteriormente foi realizada a furação da tubulação de entrada e furação da tubulação de saída para fixação dos termopares com cola, em seguida, foi montado o medidor de vazão na tubulação de entrada do calorímetro.

A etapa final da construção foi colar a vedação ao redor de todo calorímetro na parte interna, composta de espuma com as dimensões de $20 \mathrm{~mm}$ de largura e $10 \mathrm{~mm}$ de espessura, posteriormente foram soldadas as fechaduras, com solda MAG e realizado a pintura do calorímetro na cor preta. O esquema completo do calorímetro pode ser observado na Figura 7. 


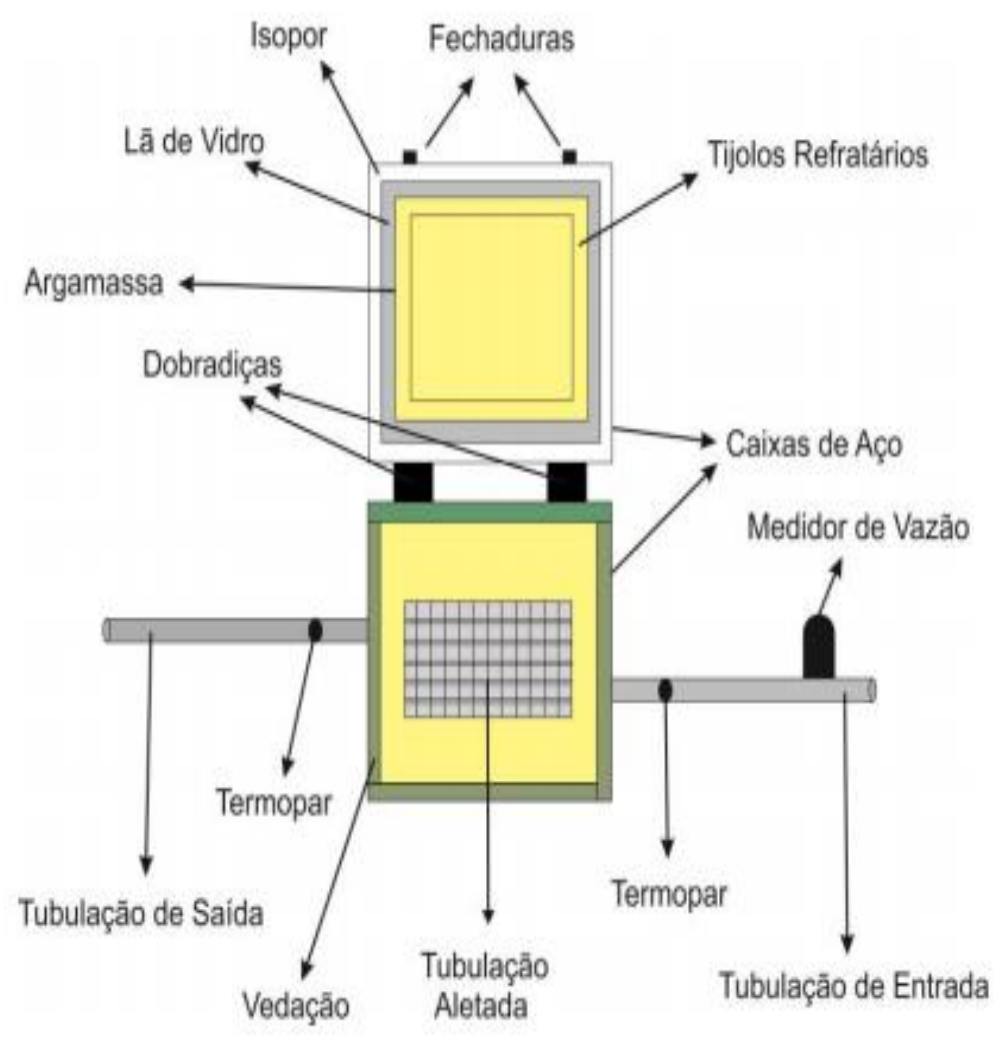

Figura 7: Esquema completo do calorímetro

\subsection{Testes Experimentais com o Calorímetro}

Para os testes experimentais foram utilizados os seguintes materiais e equipamentos: calorímetro; carro deslocador; balança de precisão, sistema de aquisição de dados, que é composto por um amplificador de sinal para os termopares, placa de aquisição de dados NI USB 6009; divisor de tensão; Shunt (500A-60mV); software "LabVIEW 2011", onde foi realizada a programação para placa de aquisição de dados; fontes de alimentação CC - Nadal; computador; termopares tipo k; medidor de vazão; aparelho de solda Esab Warrior Feed 304W e peças de aço SAE 1020, conforme Figura 8.

Inicialmente foram instalados os drivers de aquisição de dados, no software LabVIEW. No software seleciona-se DAQ Assistant, disponível em: $1^{\circ}$ - functions; $2^{\circ}$ - Express; $3^{\circ}$ - Input; $4^{\circ}$ DAQ Assistant. Após isso, abrirá uma de configuração, então seleciona-se a função desejada, neste caso Acquire Signal. Esse sistema de aquisição de dados foi monitorado através de gráficos do tipo: Acompanhamento da tensão (V); Acompanhamento da corrente (A); Acompanhamento da vazão de água (L/min); Tempo de soldagem (s); Acompanhamento da temperatura $\left({ }^{\circ} \mathrm{C}\right)$. 


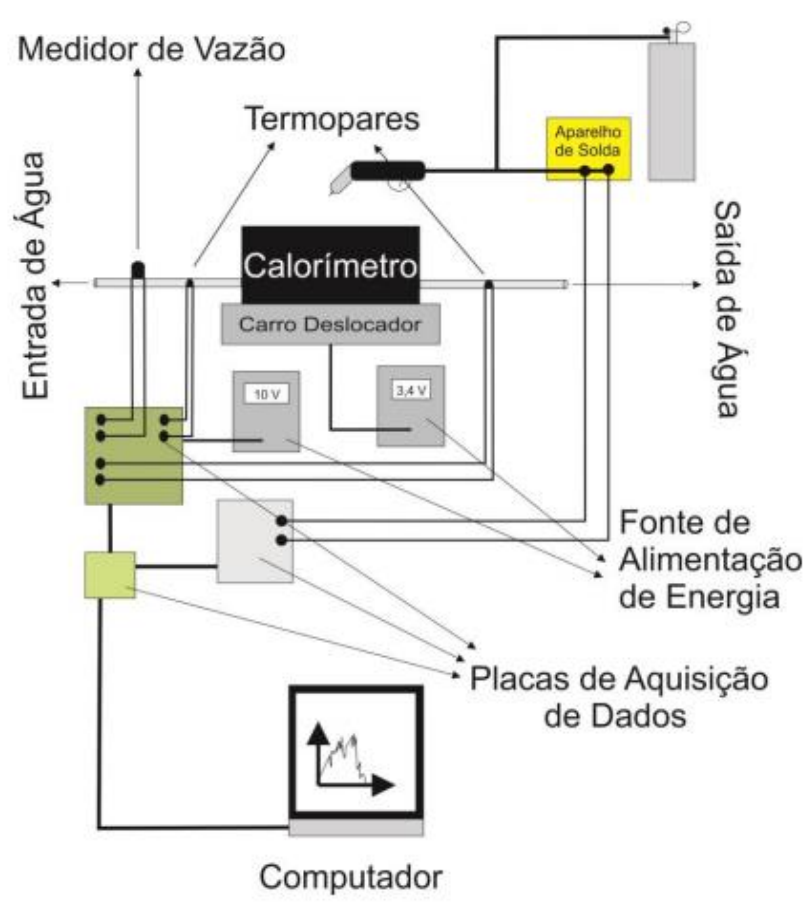

Figura 8: Desenho esquemático do sistema utilizado na determinação do rendimento térmico na soldagem

Para determinação da eficiência térmica do calorímetro foram realizados dois testes, onde o material dos testes é o aço SAE 1020, onde foi determinada a eficiência térmica do calorímetro através da diferença de calor, entre o calor cedido pela peça, e o recebido pelo calorímetro, determinando então o rendimento térmico.

No primeiro teste foi utilizada uma peça de 2028 gramas, que foi aquecida em um forno, até atingir uma temperatura de $800{ }^{\circ} \mathrm{C}$, obtendo uma variação de temperatura de $775^{\circ} \mathrm{C}$, devido a temperatura ambiente no local do teste ser de $25{ }^{\circ} \mathrm{C}$. Após o aquecimento, foi colocada a peça no interior do calorímetro, para que a mesma realizasse a trocar de calor com o calorímetro. Dentro da tubulação alentada passava água a uma vazão constante $0,000021 \mathrm{~m}^{3} / \mathrm{s}$. A peça ficou no interior do calorímetro durante 1191,2 segundos, tempo em que realizou-se a troca de calor entre a peça e o calorímetro, para que se pudesse realizar a aquisição dos dados necessário para realização da determinação da eficiência térmica do calorímetro.

No segundo teste foi utilizada uma peça de 3821gramas, a peça foi aquecida em um forno até atingir uma temperatura de $800^{\circ} \mathrm{C}$, obtendo uma variação de temperatura de $775^{\circ} \mathrm{C}$, devido a temperatura ambiente no local do teste ser de $25^{\circ} \mathrm{C}$. Após o aquecimento, foi colocada a peça no interior do calorímetro, para que a mesma realizasse a trocar de calor com o calorímetro. Dentro da tubulação alentada passava água a uma vazão constante de $0,000021 \mathrm{~m}^{3} / \mathrm{s}$. A peça ficou no interior do calorímetro durante 1762,3 segundos, tempo em que se realizou a troca de calor entre a peça e o calorímetro, para que se pudesse realizar a aquisição dos dados necessária para realização da determinação da eficiência térmica do calorímetro. 


\subsection{Testes Experimentais do Rendimento Térmico da Soldagem}

No experimental do rendimento térmico da solda, foi realizado um teste de solda, onde se utilizou uma peça do material de aço SAE 1020 com as dimensões de $120 \mathrm{~mm} \times 50 \mathrm{~mm} \times 10 \mathrm{~mm}$. No mesmo, foi realizado o cordão de solda de aproximadamente $100 \mathrm{~mm}$ na peça a ser experimentada que se localizava no interior do calorímetro. Nesse momento o calorímetro estava aberto para que pudesse ser realizada a soldagem, o carro deslocador movimentou o calorímetro para que se tivesse uma velocidade constante na solda. A solda foi realizada utilizando os parâmetros demonstrados na Tabela 1.

Tabela 1. Parâmetros da soldagem

\begin{tabular}{|c|c|}
\hline Tipo de Gás & $\mathrm{CO} 2$ \\
\hline Vazão do Gás & $0,00025 \mathrm{~m}^{3} / \mathrm{s}$ \\
\hline Velocidade do Arame & $0,283 \mathrm{~m} / \mathrm{s}$ \\
\hline Velocidade de Soldagem & $1,48 \mathrm{~mm} / \mathrm{s}$ \\
\hline Tempo de Soldagem & $67,7 \mathrm{~s}$ \\
\hline Diâmetro do Arame & $0,8 \mathrm{~mm}$ \\
\hline
\end{tabular}

Após a realização da solda, foi fechado o calorímetro com a peça em seu interior para que a peça realizasse a trocar de calor com o calorímetro. Dentro da tubulação alentada, passava água a uma vazão constante de $0,0000211 \mathrm{~m}^{3} / \mathrm{s}$, a peça ficou no interior do calorímetro durante 966,9 segundos. Tempo em que se realizou a troca de calor entra a peça e o calorímetro, para que se pudesse efetuar a aquisição dos dados necessária para realização da determinação do rendimento térmico da soldagem.

\section{RESULTADOS E DISCUSSÃO}

\subsection{Funcionamento Do Calorímetro}

O calorímetro funciona de forma que a energia térmica, que consiste no calor retirado da peça é transmitida para a água. O calor transferido é monitorado por meio do aumento da temperatura da água depois de ser submersa a placa de teste no calorímetro. É inicializado o sistema de aquisição, conjuntamente com passagem do fluxo de água. Antes de colocar a peça no seu interior do calorímetro, a peça que foi aquecida pelo forno ou soldada, foi acondicionada no interior do calorímetro conforme Figura 9. O calorímetro foi fechado, iniciando-se o processo de transferência de calor do corpo de maior temperatura (peça) para o corpo de menor temperatura (tubulação aletada). Esse processo se finalizou no momento em que foi verificado, junto ao computador, no software "LabVIEW 2011", o momento em que a peça transferiu seu calor através da temperatura indicada pelo software, voltando a temperatura inicial do experimento. 


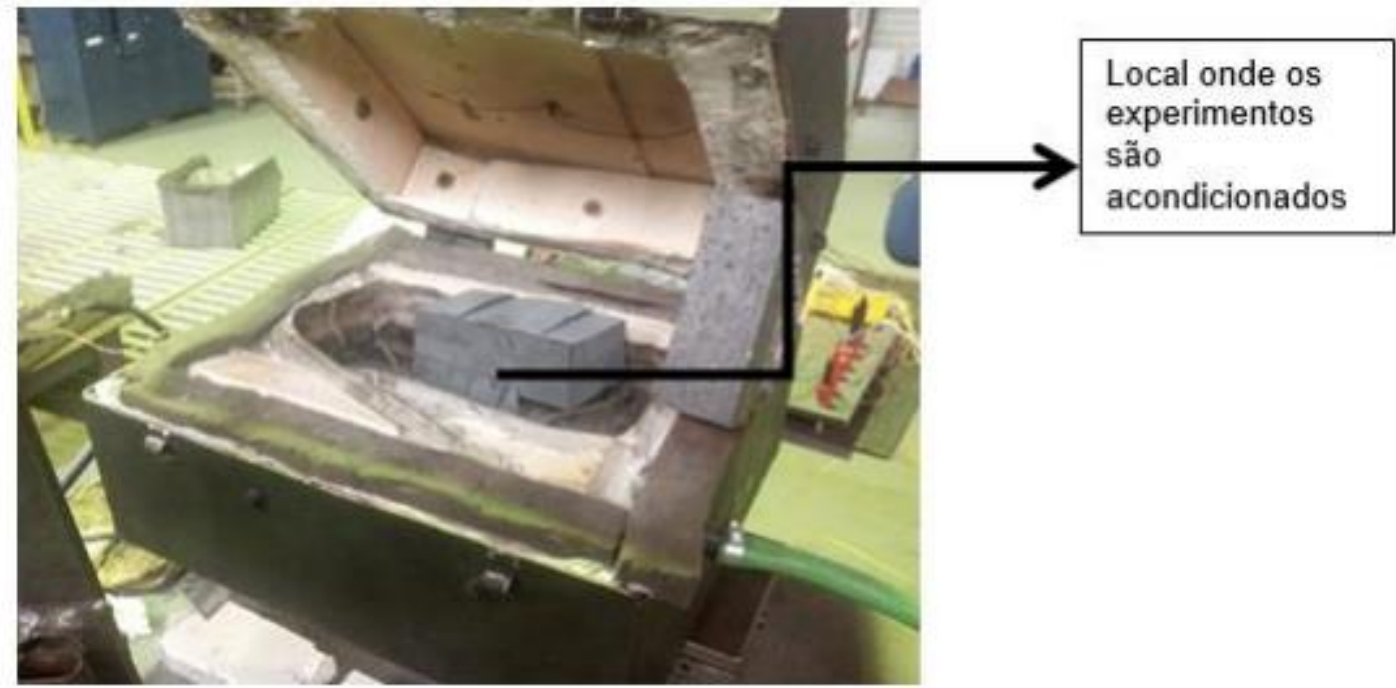

Figura 9: Local onde os experimentos são acondicionados

Na figura 10 é demostrado todo o experimento montado.

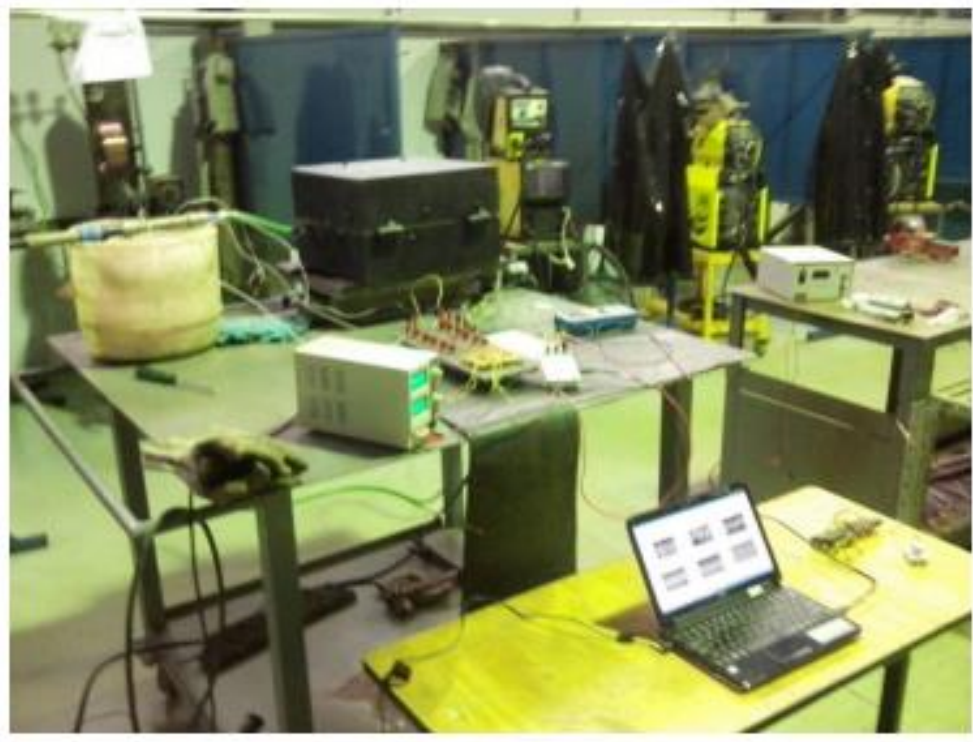

Figura 10: Experimento completo montado

\subsection{Resultados Da Eficiência Térmica Do Calorímetro}

No primeiro teste, primeiramente foi realizado o cálculo de quantidade de calor cedida (Q) pela peça para o calorímetro, usando valores da massa da peça $(\mathrm{m})$ de $2028 \mathrm{~g}$, variação de temperatura $(\Delta t)$ da peça com o ambiente onde foi realizado o teste de $775{ }^{\circ} \mathrm{C}$, e o calor específico do aço (c). Aplicando a equação fundamental da calorimetria, Equação 3, se obteve um resultado de $Q=788364,72 \mathrm{~J}$.

$Q=m \times c \times \Delta t$ 
Para determinação da quantidade de calor absorvida pelo calorímetro, foram utilizados valores como vazão da água $0,0000210 \mathrm{~m}^{3} / \mathrm{s}$, sendo que com isso foi possível a determinação da massa de água no tempo em que a peça resfriou no interior do calorímetro que foi de 1191,2 s, calor específico da água e variação de temperatura média expresso na Figura 11.

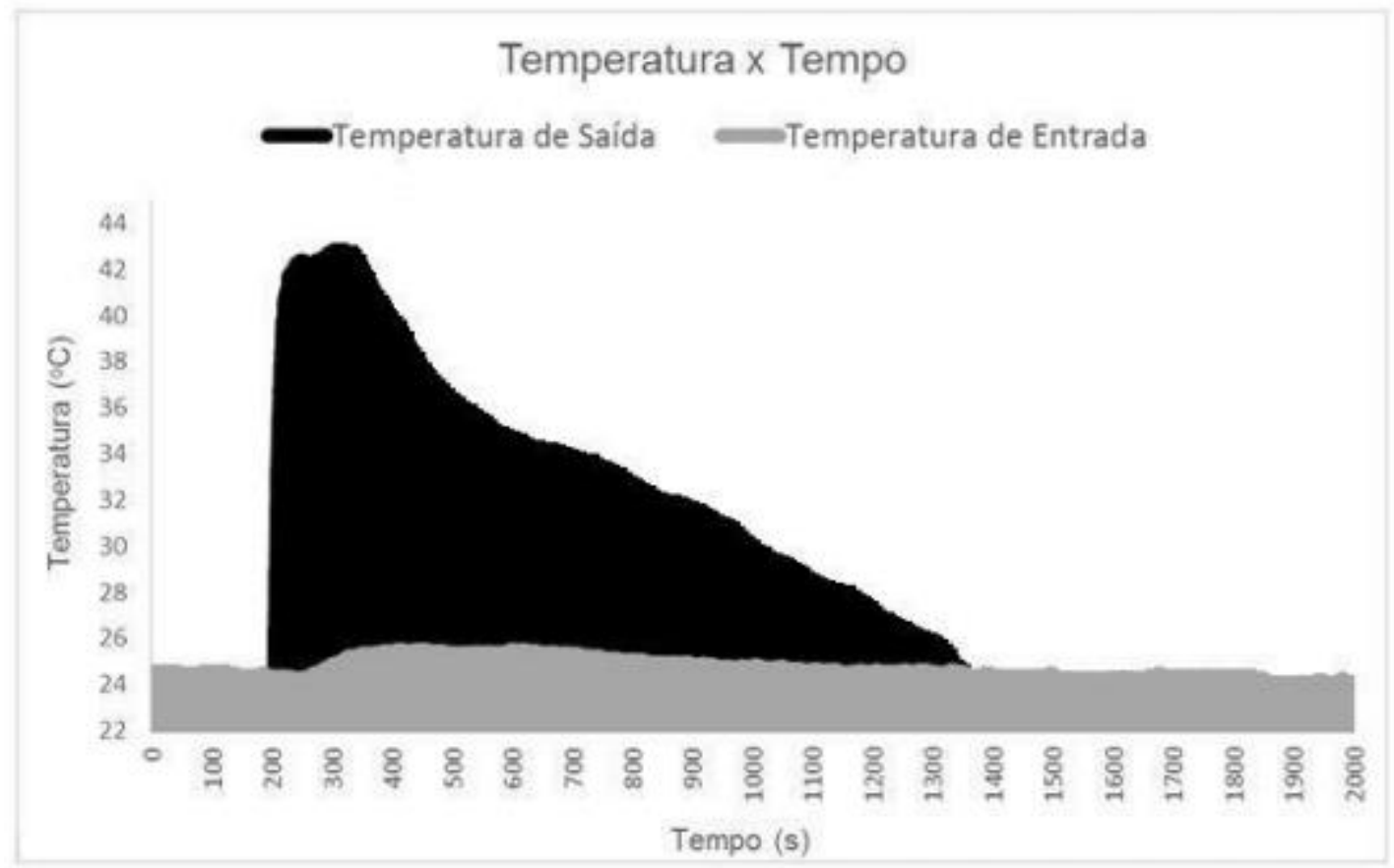

Figura 11. Temperatura de entrada e saída em função do tempo para teste 1

Aplicando a equação fundamental da calorimetria (Equação 3) obteve-se um resultado de $Q=731642,12 \mathrm{~J}$.

Fazendo a subtração entre a quantidade de calor cedida pela peça e a quantidade de calor recebida pelo calorímetro, obteve-se o valor de $Q=56722,6 \mathrm{~J}$, que corresponde a uma perda de calor de 7,19\%. Tendo uma eficiência de $92,81 \%$.

No segundo teste, primeiramente, foi realizado o cálculo de quantidade de calor cedida pela peça para o calorímetro, usando valores da massa da peça de $3821 \mathrm{~g}$, variação de temperatura da peça com o ambiente onde foi realizado o teste de $750{ }^{\circ} \mathrm{C}$, e o calor específico do aço. Aplicando a equação fundamental da calorimetria (Equação 1), se obteve um resultado de $\mathrm{Q}=1485375,5 \mathrm{~J}$.

Para determinação da quantidade de calor absorvida pelo calorímetro, foram utilizados valores como vazão da água de $0,0000211 \mathrm{~m}^{3} / \mathrm{s}$, sendo que com isso foi possível a determinação da massa de água no tempo em que a peça resfriou no interior do calorímetro igual a 1762,3s, calor específico da água e valor da temperatura média expressa na Figura 12. 


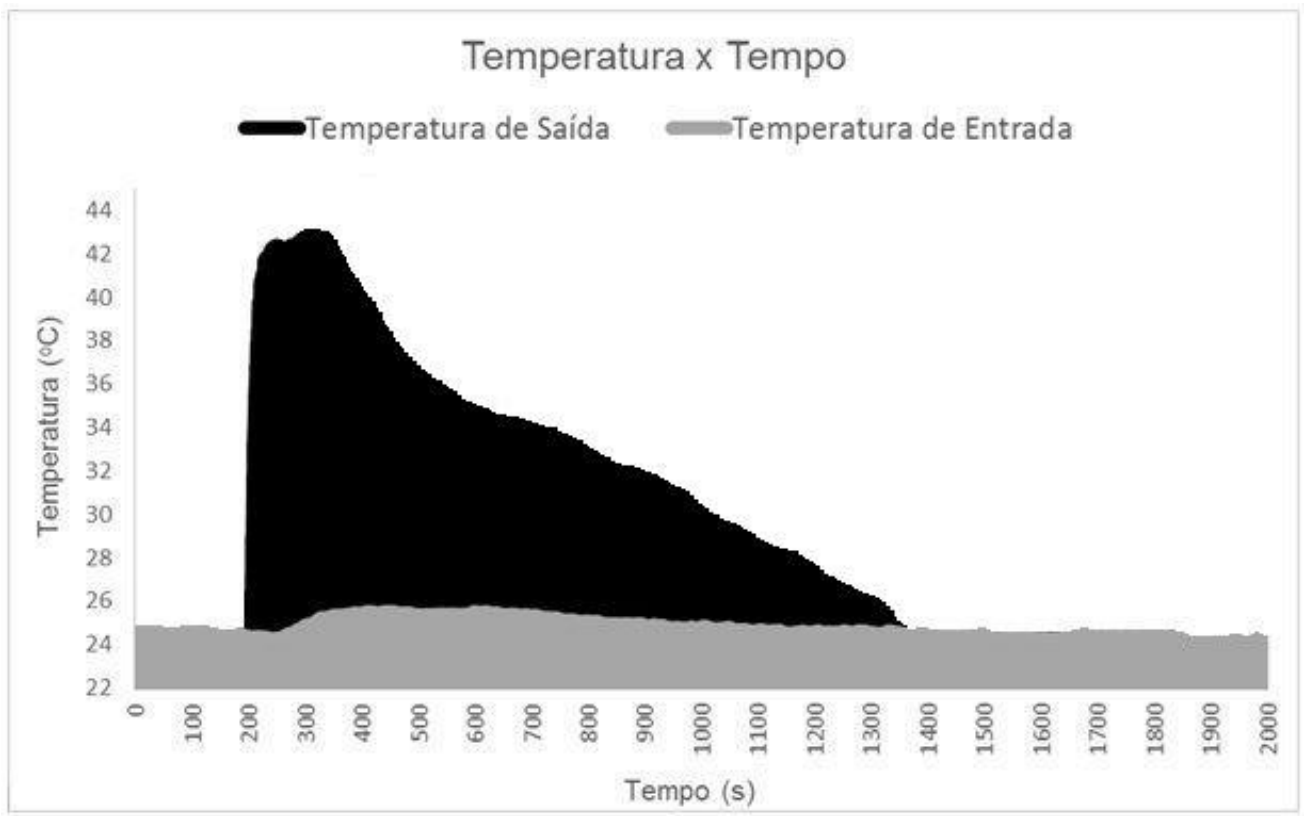

Figura 12: Temperatura de entrada e saída em função do tempo para teste 2

Aplicando a equação fundamental da calorimetria (equação 3) obteve-se um resultado de $Q=1346019,82 \mathrm{~J}$.

Fazendo a subtração entre a quantidade de calor cedida pela peça e a quantidade de calor recebida pelo calorímetro, obteve-se o valor de $Q=139355,68 \mathrm{~J}$, que corresponde a uma perda de calor de 9,38\%, tendo uma eficiência de 90,62\%.

\subsection{Resultado do Rendimento Térmico da Soldagem}

Para determinação do rendimento térmico da soldagem foram utilizados valores obtidos de corrente e tensão que multiplicados, demonstram o valor de potência conforme a Figura 13 o tempo de soldagem, o calor específico da água, a vazão da água e a variação entre temperatura de entrada e saída que corresponde a área preta da Figura 14.

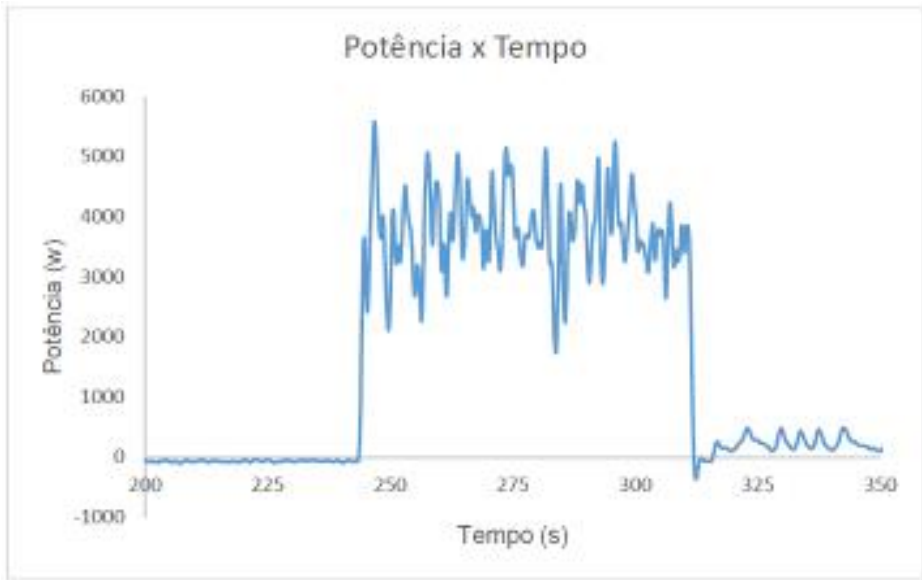

Figura 13: Potência do ponto de soldagem em função do tempo 


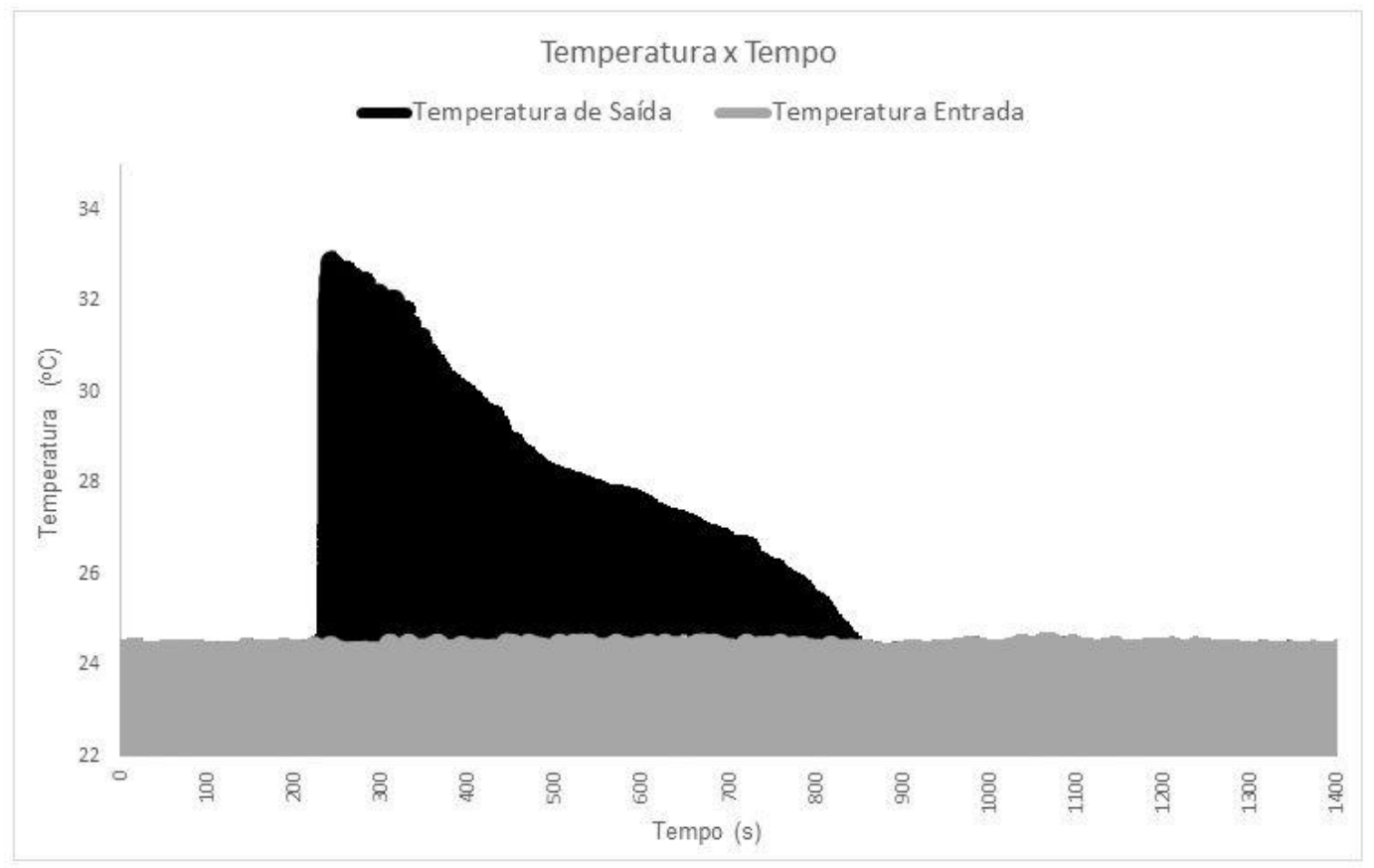

Figura 14: Variação da temperatura de entrada e de saída em função do tempo

Aplicando a Equação 1 e utilizando o método de Newton Cotes, temos uma eficiência térmica $(\Delta \mathrm{t})$ de $88,73 \%$, que está de acordo com a literatura existente que afirma que o rendimento térmico do processo de soldagem MIG/MAG (GMAW) é entre $75 \%$ e $95 \%$.

\section{CONCLUSÕES}

Foi desenvolvido um dispositivo para determinação da eficiência térmica em soldagem. Conclui-se que o calorímetro construído é capaz de realizar medições de eficiência térmica em soldagem.

Com os experimentos realizados com peças aquecidas, e cálculos de quantidade de calor cedida pela peça, e quantidade de calor recebido pelo calorímetro, verificou-se que no primeiro teste o calorímetro demostrou possuir uma eficiência térmica de $92,8 \%$ e no segundo teste uma eficiência térmica de 90,62\%, tendo uma eficiência térmica média de 91,71\%.

No experimento realizado com a soldagem, através dos cálculos de rendimento térmico, foi possível observar um rendimento térmico de soldagem MAG igual a $88,73 \%$.

Com isso verificou-se que o trabalho alcançou os objetivos propostos, tanto na construção do calorímetro, como na realização dos experimentos de eficiência térmica do calorímetro, quanto na determinação da eficiência térmica da soldagem, estando de acordo com literatura existentes no que se refere a rendimento térmico de soldagem.

\section{REFERÊNCIAS}

ARÉVALO, H. D. H. (2011). Desenvolvimento e avaliação de calorímetros via nitrogênio líquido e fluxo contínuo (água) para processos de soldagem (Mestrado em Engenharia). Universidade Federal de Uberlândia.

AREVAlO, H. D. H., VILARINHO, L. O., NASCIMENTO, V. A., GARCIA, D, B, C. (2011) Projeto, 
Construção e Avaliação de Calorímetro Por N2 Liquido Para Medição do Aporte Térmico Em Soldagem. $6^{\circ}$ Congresso Brasileiro de Engenharia de Fabricação. Universidade Federal de Uberlândia (Laprosolda). Minas Gerais.

AREVALO, H. D. H., \& VILARINHO, L. O. (2012). Desenvolvimento e avaliação de calorímetros por Nitrogênio líquido e fluxo contínuo para medição de aporte térmico. Soldagem e Inspeção, São Paulo, 17(3), 236-250.

BOSWORTH, M. R. (1991). Effective heat input in pulsed current gas metal arc welding with solid wire electrodes. Welding journal, 70(5), 111-s.

CANTIN, G. M. D., \& FRANCIS, J. A. (2005). Arc power and efficiency in gas tungsten arc welding of aluminium. Science and Technology of welding and joining, 10(2), 200-210.

DUPONT, J. N., \& MARDER, A. R. (1995). Thermal efficiency of arc welding processes. Welding Journal-Including Welding Research Supplement, 74(12), $406 \mathrm{~s}$.

ESSERS, W. G., \& WALTER, R. (1981). Heat transfer and penetration mechanisms with GMA and plasma-GMA welding. Welding Journal, 60(2), 37-42.

FUERSHBACH, P. K., KNOROVSKI, G. A. (1991). A Study of Melting Efficiency in Plasma Arc and Tungsten Arc Welding. Welding Journal, 287S-297S.

GIEDT, W. H., DUPONT, J. N., MARDER, A. R. (1989). Welding efficiency: calorimetric and temperature field measurements. Welding journal , 68 (1), 28S-32S.

HAELSIG, A., KUSCH, M., \& MAYR, P. (2012). New findings on the efficiency of gas shielded arc welding. Welding in the World, 56(11), 98.

HALLIDAY, D.; RESNICK, R.; WALKER, J. (2009). Fundamentos da Física. Vol 2, 8 ed. Rio de Janeiro. LTC Editora.

HALLIDAY, D.; RESNICK, R.; WALKER, J. (2002). Fundamentos de Física 2: Gravitação, Ondas e Termodinâmica, Vol. 2, 6a Edição. Rio de Janeiro, LTC.

KOU, S. G. (2002). A jump-diffusion model for option pricing. Management science, 48(8), 10861101.

LU, J., KOU, S. (1989). Power Inputs in Gas Metal Arc Welding of Aluminum - Part 2. Welding Journal, Vol. 68, No. 11, pp. 452s-456s.

MODENESI, P. J., MARQUES, P. V., \& SANTOS, D. B. (2012). Introdução à metalurgia da soldagem. Belo Horizonte: UFMG.

PEPE, F., LOVIS,C., SÉGRANSAN, D. (2011). Measuring the Process Efficiency of Controlled Gas Metal Arc Welding Processes. Science and technology of welding and Joing.

SGARBI, P. V. (2013). Construção e validação de um calorímetro com vazão contínua de água para avaliação do rendimento térmico em processos de soldagem (Dissertação de Mestrado). Universidade Federal do Estado do Rio Grande do Sul. 